\title{
Sistem Informasi Pelayanan Jasa Laundry Pada Doctor Laundry Coin Depok
}

\author{
Endah Wiji Lestari ${ }^{{ }^{*}}{ }$, Dahlia ${ }^{2}$, Dwi Puji Hastuti ${ }^{2}$ \\ ${ }^{1}$ Rekayasa Perangkat Lunak; Universitas Bina Saran Informatika; Jl.Kramat Raya No. 98 \\ Senen Jakarta Pusat,Tlp. (021) 23231170; e-mail: endah.ewl@bsi.ac.id \\ 2 Sistem Informasi; Universitas Bina Sarana Informatika; J.Kramat Raya No. 98 Senen Jakarta \\ Pusat,Tlp. (021) 23231170; e-mail: dahlia.dlx@bsi.ac.id, endah.ewl@bsi.ac.id \\ *Korespondensi: e-mail: endah.ewl@bsi.ac.id
}

Diterima: 30 November 2020; Review: 7 Desember 2020; Disetujui: 15 Desember 2020;

Cara sitasi: Lestari EW, Dahlia, Hastuti DP. 2020. Sistem Informasi Jasa Laundry Pada Doctor Laundry Coin Depok. Informatics for Educators and Professionals. Vol 5 (1): 83 - 92.

\begin{abstract}
Abstrak: Doctor Laundry Coin merupakan sebuah usaha yang bergerak dibidang pelayanan jasa pencucian baju dengan mesin cuci maupun mesin pengering otomatis dengan menggunakan cairan pembersiih dan pewangi khusus. Berdasarkan apa yang ada di lapangan, Doctor Laundry Coin dalam melakukan pelayanan jasa kepada pelanggan masih menggunakan sistem manual dimana setiap kegiatannya masih dicatat didalam buku besar. Hal ini menimbulkan permasalahan seperti penyimpanan data pelanggan yang kurang akurat, kesulitan dalam menemukan data pelanggan, rumitnya membuat laporan karena harus merekap banyak data, dan proses transaksi yang memakan waktu cukup lama, belum lagi jika bukti pembayaran hilang atau lupa dalam hal pencatatan transaksinya, tentu hal tersebut mempengaruhi dalam pembauatn laporan akhir. Untuk itu perlu adanya sistem yang dapat membantu mempermudah pelayanan pada Doctor Laundry Coin. Dalam pengumpulan data pada penelitian ini, penulis menggunakan metode wawancara, observasi, dan studi pustaka. Sedangkan untuk mengembangkan perangkat lunaknya menggunakan metode Prototyping dengan tahapan Pengumpulan Kebutuhan, Perancangan, Mengkodekan Sistem, Pengujian Sistem, Evaluasi Sistem, Implementasi Sistem. Hasil dari penelitian ini memberikan sistem informasi yang diusulkan kepada pihak laundry yang nantinya akan bermanfaat sehingga dalam melakukan pelayanan dan pengelolaan datanya menjadi lebih mudah, cepat, tepat, dan akurat.
\end{abstract}

Kata kunci: Jasa Laundry, Model Pengembangan Prototipe, Sistem Informasi

Abstract: Doctor Laundry Coin is a business engaged in laundry services with a washing machine or automatic drying machine using special cleaning fluids and fragrances. Based on what is in the field, Doctor Laundry Coin in providing services to customers still uses a manual system where every activity is still recorded in the ledger. This raises problems such as inaccurate customer data storage, difficulty in finding customer data, the complexity of making reports because they have to recap a lot of data, and transaction processes that take quite a long time, not to mention if proof of payment is lost or forgotten in terms of recording transactions, of course this affects the final report. For that we need a system that can help simplify services at Doctor Laundry Coin. In collecting data in this study, the authors used the interview, observation, and literature study methods. Meanwhile, to develop the software using the Prototyping method with the stages of Requirements Collection, Design, System Coding, System Testing, System Evaluation, System Implementation. The results of this study provide a proposed information system to the laundry which will later be useful so that the service and data management becomes easier, faster, more precise, and accurate.

Keywords: Information Systems, Laundry Services, Prototype Development Models 


\section{Pendahuluan}

Seiring pesatnya perkembangan teknologi, berdampak pada segala bidang kehidupan yang ada pada masyarakat. Semakin hari kesibukan masyarakat sebagai karyawan maupun pemilik bisnis semakin bertambah sehingga pekerjaan rumah yang biasa dilakukan sendiri harus membutuhkan bantuan orang lain. Karena masyarakat menginginkan kegiatan dilakukan dengan cepat, hal ini menciptakan ide bisnis yang dapat melayani kegiatan yang biasa dilakukan oleh seseorang, salah satunya adalah jasa laundry [1].

Usaha laundry merupakan sebuah bisnis yang berkaitan dengan pelayanan jasa pencucian dan pengeringan terutama pakaian. Banyaknya jasa laundry yang berkembang pesat menjadi persaingan tersendiri di sektor ini semakin ketat. Kurangnya pelayanan kepada konsumen akan menyebabkan berkurangnya konsumen atau bahkan hilang karena konsumen pindah ke tempat jasa layanan yang lainnya. Sebab itu, setiap pemilik bisnis laundry berusaha meningkatkan pelayanan kepada konsumen tersebut [2].

Sistem informasi pelayanan merupakan aplikasi komputer yang digunakan untuk bisnis yang berkaitan dengan jasa pelayanan, terutama dalam system penyimpanan dan pengolahan data maupun informasi agar dapat menjalani bisnis jasa dengan mudah dan berjalan dengan baik. Keadaan tersebut menyebabkan banyaknya perusahaan yang meningkatkan pengembangan di bidang pelayanan jasa untuk meningkatkan pelayanan yang lebih baik lagi. Salah satunya di bidang pelayanan jasa laundry. Pelayanan jasa laundry merupakan sebuah bisnis yang berkaitan dengan jasa pencucian pakaian dengan mesin cuci maupun mesin pengering otomatis dan cairan pembersih serta pewangi khusus. Bisnis ini menjamur di kotakota besar yang banyak terdapat rumah kost, rumah kontrakan, dimana penyewa kost atau kontrakan tak sempat atau tak biasa melakukan cuci dan setrika baju sendiri dikarenakan kesibukan sebagai mahasiswa maupun pekerja. Tak berhenti sampai disitu, kombinasi antar layanan murah dengan layanan cuci-setrika berkembang lebih kreatif lagi dengan munculnya laundry kiloan. Yaitu laundry biasa, tetapi harga yang dibayarkan berdasarkan hitungan kilogram (bukan per potong pakaian). Inilah bisnis yang sangat pesat pada masa sekarang, dimana banyak sekali disekitar kita pelayanan jasa laundry kiloan, dan tidak sedikit orang yang memanfaatkan pelayanan jasa laundry tersebut.[3]

Doctor Laundry Coin adalah sebuah usaha rumahan yang bergerak di bidang jasa pelayanan pencucian pakaian yang bertempat di Depok. Penulis melakukan observasi pada toko guna mengetahui bagaimana proses transaksi yang saat ini berjalan pada toko. Proses Bisnis yang saat ini berjalan dalam pelayanannya masih menggunakan sistem konvensional, dimana dalam melakukan pencatatan data pelanggan, mencatat transaksi laundry yang masuk masih ditulis dalam buku besar dan menggunakan nota tertulis untuk bukti transaksinya. Dengan proses penyimpanan data transaksi yang seperti itu, maka akan banyak data transaksi yang menumpuk atau bisa saja terlewat dalam proses pencatatannya. Permasalahan yang lain yang sering terjadi adalah seperti data pelanggan yang kurang akurat, sulit dalam menemukan data pelanggan, kesalahan penulisan jumlah transaksi atau tidak jelasnya tulisan, rumitnya membuat laporan transaksi karena harus merekap banyak data, mencari bukti nota yang lama atau hilang dan untuk transaksi yang sudah lama, bisa saja hilang karena sobek atau kusam, dengan masalah tersebut dapat memperlambat proses yang akan dijalankan setelahnya. Dalam perkembangan jaman yang sudah sangat canggih dengan kehadiran teknologi baru saat ini tentunya sudah sangat tertinggal untuk sistem yang berjalan saat ini pada jasa usaha tersebut, oleh karena itu penulis ingin membuat sebuah sistem informasi pelayanan menggunakan aplikasi komputer yang digunakan untuk bisnis yang berkaitan dengan jasa pelayanan, terutama dalam sistem penyimpanan dan pengolahan data maupun informasi agar dapat menjalani bisnis jasa dengan mudah dan sudah terkomputerisasi. Dengan demikian dapat membantu mempermudah pelayanan transaksi pada Doctor Laundry Coin, yang nantinya diharapkan dapat mempermudah petugas untuk menginput transaksi yang terjadi serta membuat laporan dan menghitung laporan keuangannya.

Berdasarkan permasalahan yang telah diuraikan, maka permasalahan dapat disimpulkan sebagai berikut : 1 . Tidak adanya media yang dapat digunakan oleh petugas dalam pencatatan transaksi hariannya atau bulanannya, 2. Perlu adanya sistem pendukung untuk dapat mengelola keuangan, 3. Merancang sebuah sistem yang nantinya dapat mempermudah, mempercepat petugas dalam mengelola transaksi yang terjadi dan membuat laporan keuangannya.

Sistem informasi sebagai suatu alat untuk menyajikan informasi dengan cara 
sedemikiam rupa sehingga bermanfaat bagi penerimanya". Tujuannya adalah untuk menyajikan informasi guna pengambilan keputusan pada perencanaan, pemrakarsaan, pengorganisasian, pengendalian kegiatan operasi subsistem dan menyajikan sinergi organisasi pada proses Menurut Alfatta dalam [4]. Berikut sistem informasi berdasarkan konsep (input,processing,output). Menjelaskan kronologis penelitian, termasuk desain penelitian, prosedur penelitian (dalam bentuk algoritma, Pseudocode atau lainnya), bagaimana untuk menguji dan akuisisi data. Deskripsi dari program penelitian harus didukung referensi, sehingga penjelasan tersebut dapat diterima secara ilmiah.

Entity Relationship Diagram (ERD) adalah suatu model jarinagan yang menggunakan susunan data yang disimpan dalam sistem informasi secara abstrak [5]. ERD merupakan suatu model yang diguanakan untuk menjelaskan hubungan antar data dalam basis data berdasarklan objek-objek dasar data yang mempunyai hubungan antar relasi [6]. ERD berfungsi untuk memodelkan struktur data dan hubungan antar data, untuk menggambarkannya diguanakan beberapa notasi dan simbol. Pada dasarnya ada tiga simbol yang digunakan, yaitu: Entity, merupakan objek yang mewakili sesuatu yang nyata dan dapat dibedakan dari sesuatu yang lain. Entity juga yaitu sesuatu yang dapat dibedakan dalam dunia nyata di mana informasi yang berkaitan dengannya dikumpulkan. Simbol dari entity ini biasanya digambarkan dengan persegi panjang. Relationship, adalah hubungan yang terjadi antara satu entity atau lebih entity. Relationship tidak memiliki keberadaan fisik, kecuali yang mewarisi hubungan antara entity tersebut. Simbol yang digunakan adalah bentuk belah ketupat, diamond atau rectangle. Atribute adalah karakteristik dari entity atau relationship yang menyediakan penjelasan detail tentang atau relationship tersebut. Atribut value (nilai atribute) adalah suatu data aktual atau informasi yang disimpan di suatu atribute di dalam suatu entity atau relationship. Terdapat dua jenis atribute, yaitu Identifier (key), untuk menentukan suatu entity secara unik. Dan Descriptor (nonkey atribute), untuk menentukan karakteristik dari suatu entity yang tidak unik.

\section{Metode Penelitian}

Sistem informasi sebagai suatu alat untuk menyajikan informasi dengan cara sedemikiam rupa sehingga ber-manfaat bagi penerimanya". Tujuannya adalah untuk menyajikan informasi guna pengambilan keputusan pada perencanaan, pemrakarsaan, pengorgan-isasian, pengendalian kegiatan operasi subsistem dan menyajikan sinergi organisasi pada proses Menurut Alfatta dalam

Prototype merupakan suatu metode atau proses dimana developer membuat sebuah model perangkat lunak, apabila client tidak bisa memberikan informasi mengenai kebutuhan yang diinginkan secara maksimal. Prototype bisa juga diartikan sebagai metode pengembangan perangkat lunak yang sebelumnya menjadi sebuah sistem yang final [7]. Tahapan proses dalam model prototyping adalah sebagai berikut :1. Pengumpulan KebutuhanDeveloper dan klien akanbertemu terlebih dahulu dan kemudian menetukan tujuan umum, kebutuhan yang diketahui dan gambaran bagian-bagian yang akan dibutuhkan berikutnya, 2. Perancangan Perancangan dilakukan dengan cepat dan rancangan tersebut mewakili semua aspek software yang diketahui, dan rancangan ini menjadi dasar pembuatan prototype, 3. Mengkodekan Sistem Dalam tahap ini prototyping yang sudah disepakati diterjemahkan kedalam bahasa pemrograman yang sesuai, 4. Pengujian Sistem Setelah sistem sudah menjadi suatu perangkat lunak yang siap pakai, harus dites dahulu sebelum digunakan. Ini dilakukan dengan White Box, Black Box, Basis Path, pengujian arsitektur dan lain-lain, 5. Evaluasi Sistem Pelanggan mengevaluasi apakah sistem yang sudah jadi sudah sesuai dengan yang diharapkan. Jika sudah, maka langkah ketujuh dilakukan, jika belum maka mengulangi langkah 2 dan 3, 6 . Implementasi Sistem Perangkat lunak yang telah diuji dan diterima pelanggan siap untuk digunakan.

Hasil Peneliatian Sebelumnya mengenai jasa laundry :

Pelayanan jasa laundry pada 21 Laundry Padang merupakan sebuah bisnis yang bergerak di bidang jasa pencucian pakaian dengan mesin cuci maupun mesin pengering otomatis dengan menggunakan cairan pembersih dan pewangi khusus. pengelolaan data transaksi belum menggunakan sistem terkomputerisasi. Proses pencatatan data pelanggan, data transaksi, dan pembuatan nota penyerahan yang masih dilakukan secara manual dimana setiap kegiatannya disimpan di dalam buku besar. Oleh karena sistem penyimpanan data masih berupan pengarsipan fisik sehingga sering terjadi penumpukan arsip yang dapat membuat keamanan data kurang terjamin. Proses pembuatan laporan transaksi, pencarian data yang 
lambat, dan penghitungan data dalam jumlah banyak sulit dilakukan dan menimbulkan permasalahan dalam administrasi. Menjadi pilihan para pengguna untuk dapat mengakses informasi kapan dan dimana saja sehingga mempercepat aliran informasi. Penggunaan sistem dengan fitur mobile ini memudahkan pelanggan untuk melihat notifikasi status cucian mereka yang telah selesai, riwayat transaksi, dan rincian data transaksinya. Oleh karena itu, perlu dibangun sebuah sistem informasi berbasis web dengan fitur mobile pada 21 Laundry Padang yang nantinya diharapkan dapat menunjang aktivitas dan keberhasilan bisnis pada perusahaan [8]

Hello Laundry yang beralamat di Jalan Depoksari Raya No 14 B Semarang, dimana usaha laundry ini menyediakan jasa cuci kiloan diantaranya jasa cuci dan kering, cuci dan kering dan setrika, cuci bed cover, cuci selimut tipis sampai selimut tebal. Selama ini proses administrasi pelayanan masih menggunakan kegiatan manual. Transaksi penerimaan laundry masih di catat dalam nota penerimaan laundry. Sehingga untuk melakukan pencarian data mengalami kesulitan dan membutuhkan proses yang lama. Serta untuk mengetahui pendapatan laundry juga harus melakukan rekapitulasi semua nota penerimaan laundry. Selain itu pendataan pembelian barang untuk keperluan Hello laundry juga masih menggunakan pendataan manual sehingga untuk mengetahui jumlah pengeluaran laundry membutuhkan waktu yang relatif lama. Untuk itu diharapkan ingin dibuat sistem informasi agar pencatatan pengeluaran dan pendapatan laundry dapat berjalan cepat, efektif dan efesien. [3]

Usaha laundry merupakan salah satu bisnis dibidang jasa cuci dan setrika pakaian,

usaha ini memiliki perputaran yang cepat atau rentang waktu permintaan pelanggan antara permintaan pertama dan permintaan selanjutnya pada jasa ini yang memakan waktu relatif singkat. Lebih jelasnya, pelanggan akan kembali menggunakan jasa ini ketika pakaian yang dikenakan sudah kotor. Pada era digital saat ini penerapan teknologi pada sebuah usaha laundry juga sudah diterapkan. Banyak startup-startup yang berjalan pada bisnis laundry, namun seiring nya kemajuan teknologi diharapan munculnya sebuah inovasi terbaru. Aplikasi sistem pemesanan jasa laundry (E-Laundry) berbasis android dapat dijadikan sebagai salah satu inovasi bisnis dalam usaha laundry. Dimana pada aplikasi ini menjadi suatu pusat berkumpulnya para pelaku laundry dan dapat melakukan pemesanan secara online dengan melibatkan teknologi Location Based Service (LBS). LBS pada aplikasi ini digunakan sebagai peletakan titik kordinat dari posisi para pelaku laundry yang berada disekitar konsumen berdasarkan peta pada google maps. Aplikasi ini juga dapat bertaransaksi secara digital menggunakan saldo pada aplikasi dengan melakukan scan Qr Code, selanjutnya saldo pelaku laundry akan terisi sesuai dengan tagihan. Aplikasi ini dibangun menggunakan Android Studio dan MySQL sebagai databasenya.[9]

Toko syafira laundry adalah toko yang bergerak di bidang pencucian . Sistem informasi pada toko syafira laundry saat ini masih bersifat manual. Selama ini proses administrasi pelayanan masih menggunakan kegiatan manual. Transaksi penerimaan laundry masih di catat dalam nota penerimaan laundry. Sehingga untuk melakukan pencarian data mengalami kesulitan dan membutuhkan proses yang lama. Serta untuk mengetahui pendapatan laundry juga harus melakukan rekapitulasi semua nota penerimaan laundry. Berdasarkan permasalah tersebut, penulis menganalisa dan membuat sistem informasi aplikasi jasa laundry yang menerapkan model waterfall dalam pembangunannya serta menggunakan Bahasa pemograman php dan mysql sebagai database. Sistem tersebut dalam penggunaannya berbasis desktop dengan server localhost karena sistem persediaan barang yang bersifat internal [10]

Berikut adalah Proses Bisnis yang berjalan pada Jasa laundry di Doctor Laundry Coin Depok, dimulai dari Proses Penerimaan Barang, Pencucian Barang, Pengambilan Pakaian, dan Pembuatan Laporan. 1) Proses Penerimaan Barang, pelanggan datang ke Doctor Laundry Coin dengan membawa barang yang akan dicuci kebagian administrasi. Bagian administrasi akan menghitung dan mencatat data barang kedalam nota sebanyak dua rangkap (nota merah dan nota putih) serta menginformasikan harga laundry kepada pelanggan. Data tersebut meliputi nama pelanggan, tanggal terima barang, tanggal pengambilan barang, dan harga laundry. Setelahnya pelanggan akan menerima nota putih dan melakukan pembayaran sejumlah harga laundry. Admin akan menyortir barang cucian berdasarkan jenis barangnya yang nantinya akan di proses laundry. 2) Proses Pencucian Barang, administrasi akan menyerahkan barang ke bagian pencucian dan bagian setrika untuk dilakukan proses cleaning/pencucian dan proses setrika dimana sebelumnya barang telah diberi label data pelanggan. Setelah barang bersih, 
barang diserahkan ke bagian administrasi. 3) Proses Pengembalian Pakaian, pada proses ini, pelanggan mengambil barang yang telah dicuci dengan menunjukkan nota putih yang telah diberikan sebagai tanda bukti mengambil pakaian. Admin akan mengecek pada nota merah, setelah benar pakaian bersih akan diserahkan kepada pelanggan. 4) Proses Pembuatan Laporan, berdasarkan nota merah yang digunakan sebagai arsip pembayaran, bagian administrasi kan merekap dan membuat laporan transaksi harian kedalam buku besar yang nantinya kan diserahkan kepada pemilik laundry.

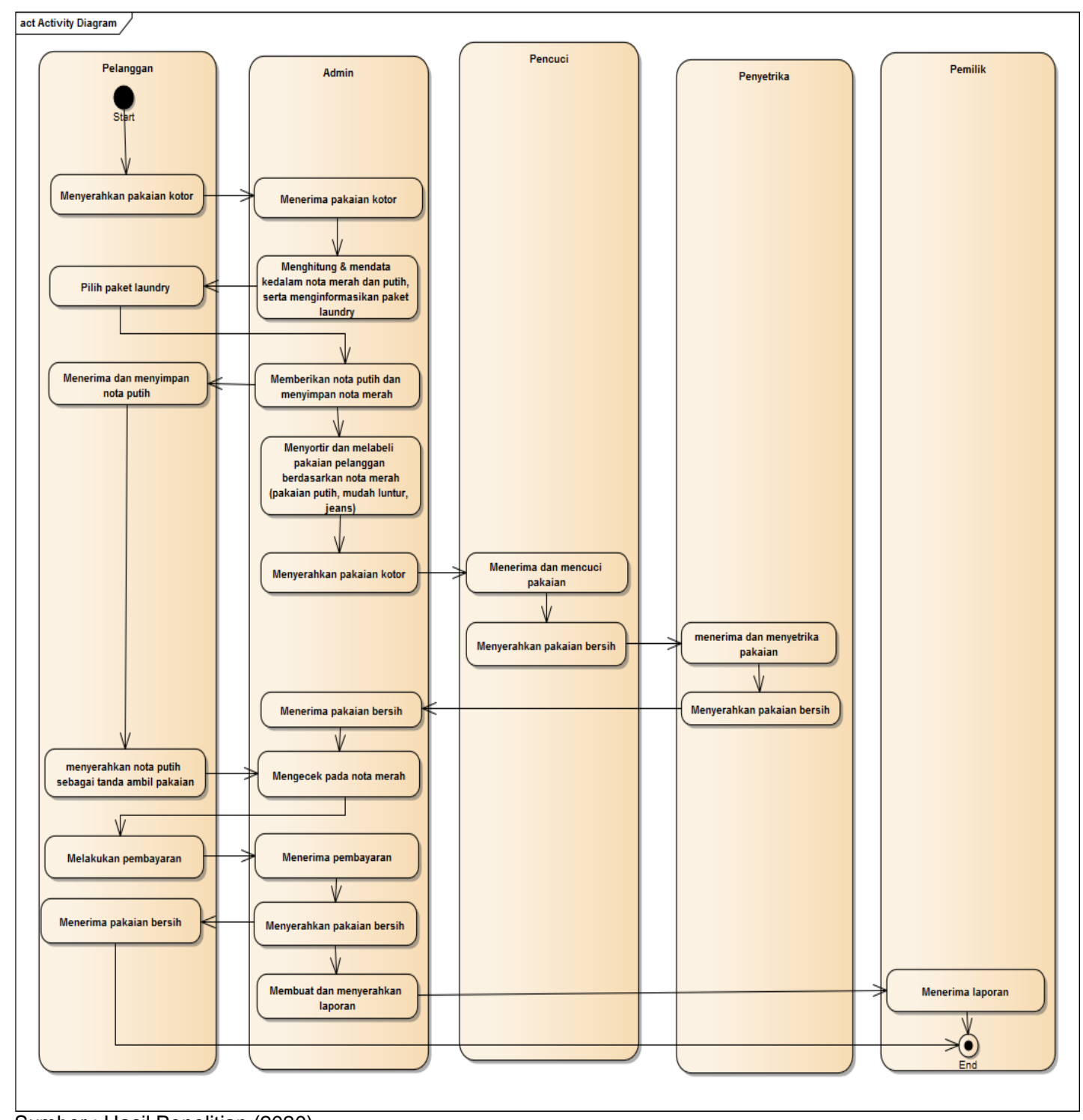

Sumber : Hasil Penelitian (2020)

Gambar 1. Analisa Sistem Berjalan

\section{Hasil dan Pembahasan}

Analisa Kebutuhan Sistem

Pada tahap ini penulis mengidentifikasikan apa saja yang dibutuhkan dalam pengembangan sistem. Analisa kebutuhan pada tahap ini terdiri dari dua bagian yaitu analisa kebutuhan sistem dan analisa kebutuhan pengguna.

Analisa kebutuhan sistem dapat di identifikasikan sebagai berikut, a). Sistem dapat menampilkan halaman login. b). Sistem dapat menampilkan halaman admin. c). Sistem dapat menampilkan halaman data pelanggan. d). Sistem dapat menampilkan halaman transaksi/penerimaan laundry. e). Sistem dapat menampilkan halaman data pembayaran/laundry selesai. f). Sistem dapat menampilkan halaman laporan. 
Analisa kebutuhan pengguna administrator sebagai berikut, a). Administrator dapat melakukan login. b). Administrator dapat mengelola halaman transaksi/penerimaan laundry. c). Administrator dapat mengelola halaman data pelanggan. d). Administrator dapat mengelola halaman pembayaran/laundry selesai. f). Administrator dapat mengelola halaman laporan.

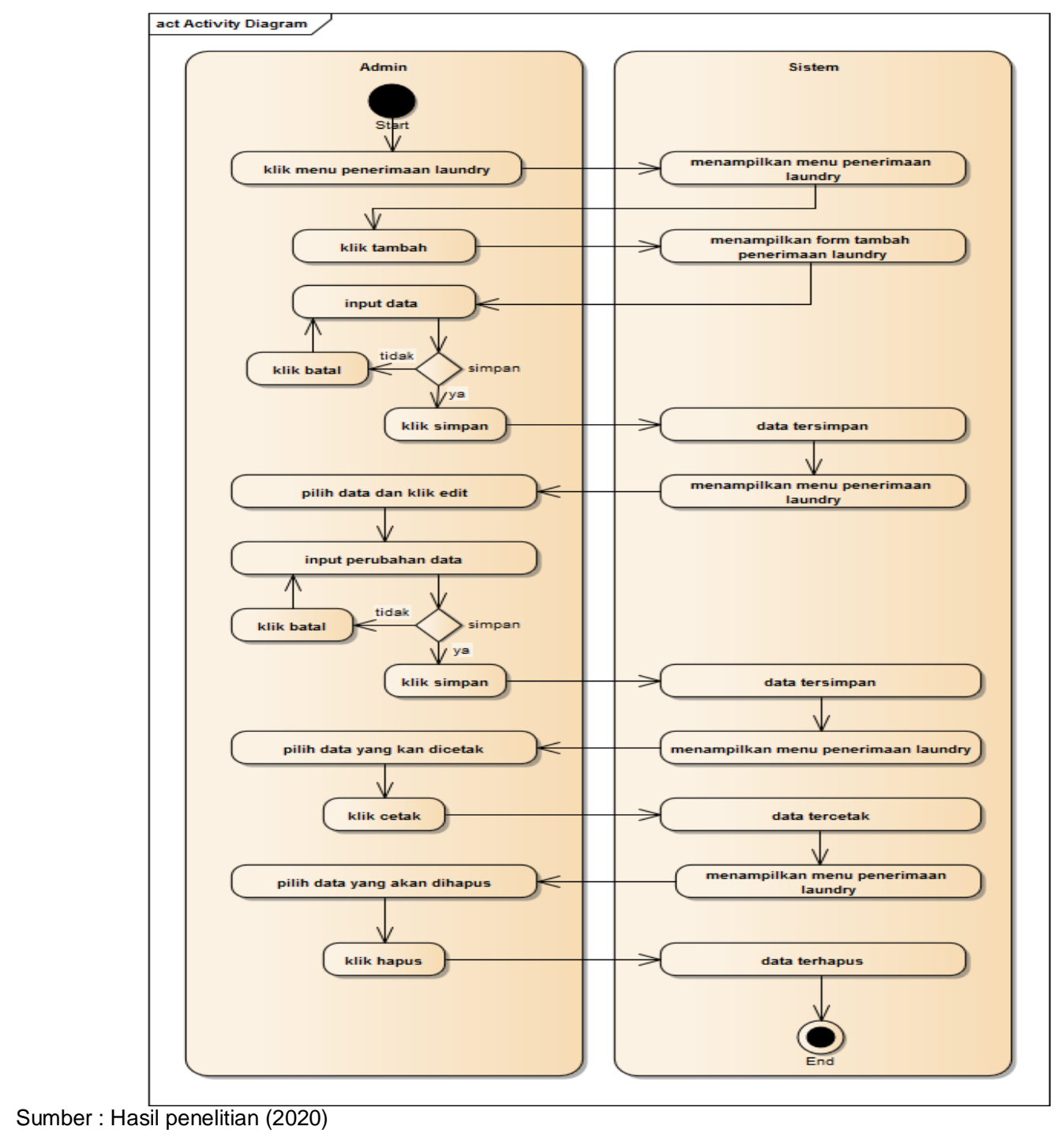

Gambar 2. Activity Diagram Penerimaan Laundry

Diagram tersebut menjelaskan proses penerimaan laundry yang akan dirancang menjadi sebuah sistem. Admin laundry mengakses menu oenerimaan laundry untuk melakukan input data laundry, setelah itu sistem menunjukan reson dengan menampilkan halaman penerimaan laundry, admin mengakses menu tambah pada sistem dan sistem menampilkan halaman untuk menginput data laundry. Setelah data laundry diinput, maka proses selanjutnya adalah penyimpanan data laundry dan atau admin bisa membatalkan proses input dengan mengaskses tombol batal. Dalam proses penyimpanansetelah data disimpan tentunya data tersebut dapat diolah berupa pengeditan, pencetakan dan penghapusan. Pada proses pengeditan admin dapat mengakses tombol edit lalu melakukan perubahan dan proses simpan jika data selesai diupdate. Untuk proses pencetakan dan penghapusan, admin dapat langsung mengakses tombol haus atau tombol cetak. 


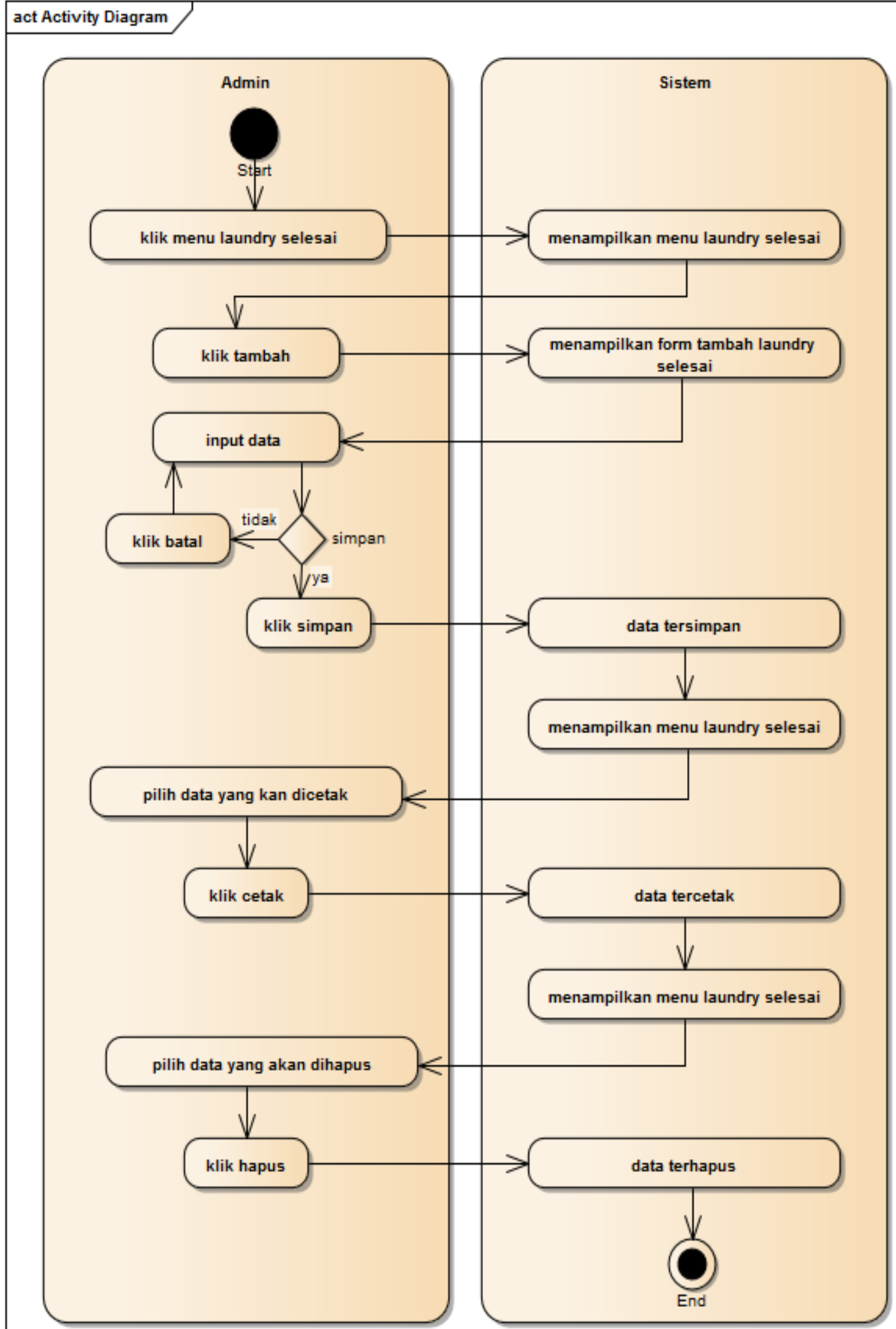

Gambar 3. Activity Diagram Laundry Selesai 
Diagram tersebut menjelaskan proses penyelesaian laundry dalm arti pakaian yang sudah selesai diproses akan diinput kembali data nya untuk mengubah statusnya agar status berubah menjadi selesai dan laundry dapat di kembalikan ke pelanggan. Prosesnya dimulai dari admin yang mengakses menu Laundry selesai, allu sistem akan menampilkan halaman laundry selesai. Admin akses tombol tambah untuk melakukan input data laundry yang sudah selesai. Admin dapat akses tombol simpan untuk menyimpan data laundry selesai. Admin dapat akses tombol hapus untuk hapus data laundry dan admin juga dapat melakukan cetak untuk data laundry selesai.

Berikut adalah Rancangan Entity Relationship Diagram dan Logical Record Structure yang terbentuk dalam penyusunan perancangan sistem informasi jasa laundry

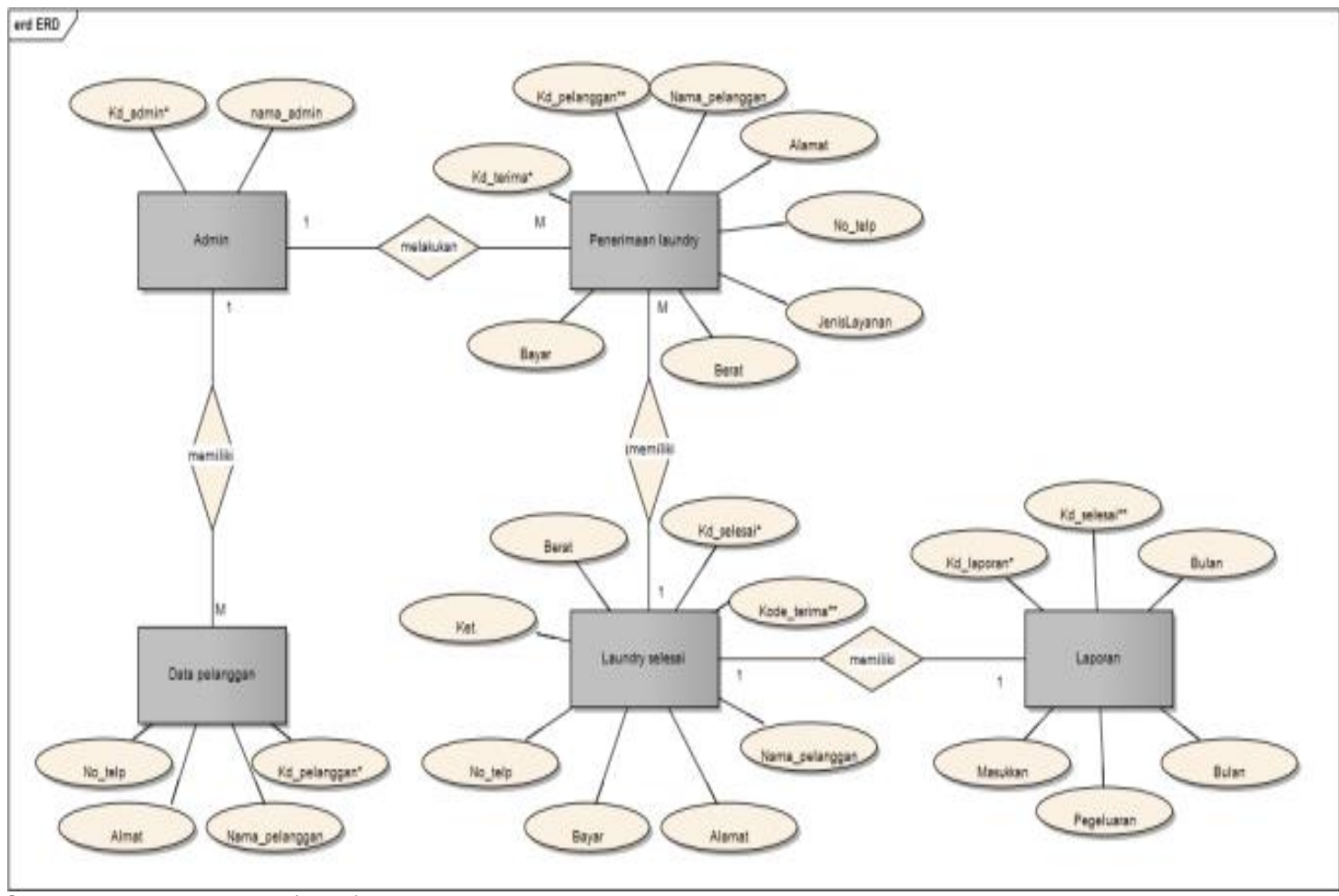

Sumber : Hasil penelitian (2020)

Gambar 4. Entity Relationship Diagram

Hasil

Hasil yang diharapkan dari adanya pengembangan sistem informasi jasa laundry ini adalah sebuah sistem terkomputerisasi yang dapat membantu mempermudah dan mempercepat dalam penginputan data pelanggan, data transaksi hingga pembuatan laporan, dimana dengan sistem tersebut dapat mempermudah pengerjaan kasir atau petugas laundry. Berikut adalah hasil Rancangan Website yang digunakan dalam pelayanan jasa laundry pada Doctor Laundry Coin Depok. 


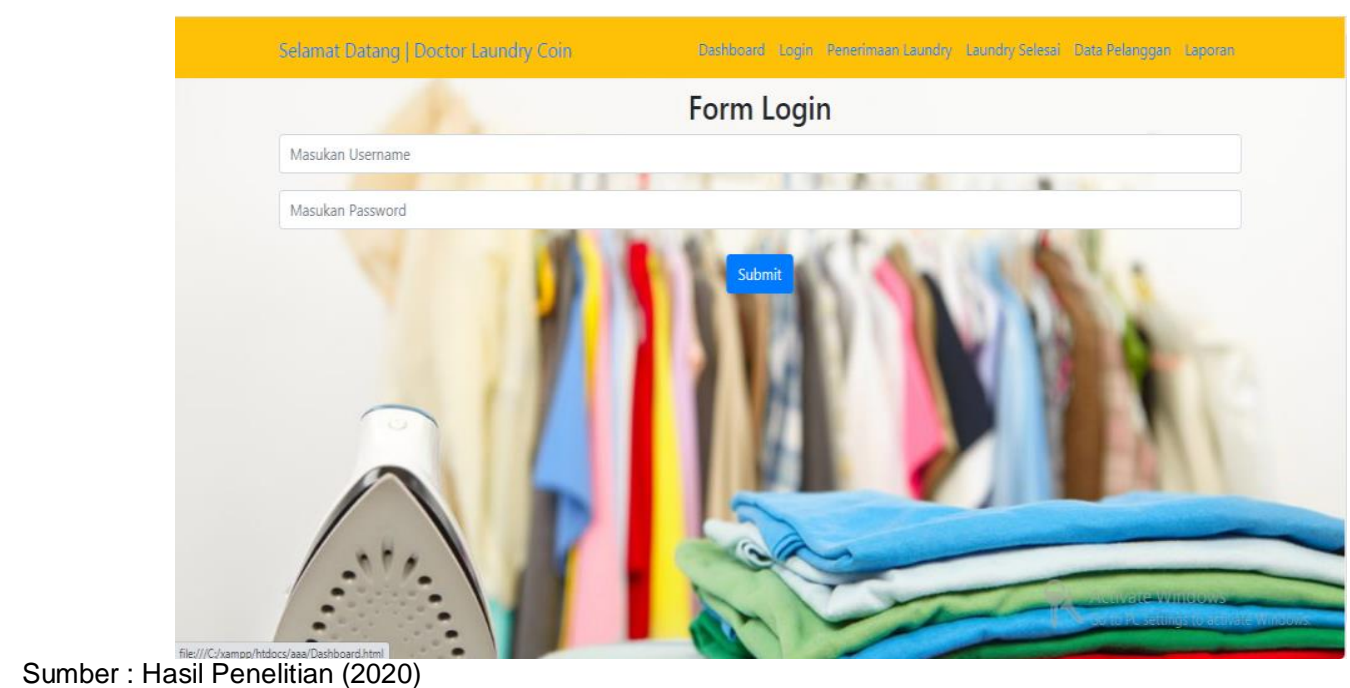

Gambar 5. Halaman Login

Desain tersebut adalah rancangan form login yang dapat diakses oleh admin laundry untuk masuk kedalam sistem laundry. Admin dapat menginput username dan password untuk dapat login ke dalam sistem. Sistem ini memiliki layanan untuk pendataan penerimaan laundry, pendataan laundry selesai, penginputan data pelanggan, dan pencetakan laporan.

Sistem laundry yang ada saat ini hanya dapat diakses oleh admin laundry dan pemilik laundry. Sistem yang ada belum dapat diakses oleh pelanggan, karena semua proses pendataan masih dilakukan oleh pihak laundry. Penulis berharap sistem yang selanjutnya dapat membuat sistem yang dimana pelanggan dapat mengakses sistem laundry, alangkah lebih nyaman nya jika pelanggan dapat memesan langsung dari rumah dan pakaiannya dapat diambil oleh pihak laundry tanpa perlu pelanggan datang langsung ke toko. Penulis berharap sistem laundry dapat mempermudah tidak hanya untuk pemilik jasa laundry tetapi juga memberikan kenyamanan bagi pelanggan dengan sistem delivery tersebut.

\section{Kesimpulan}

Jasa cuci dan setrika atau laundry yang dibutuhkan banyak masyarakat saat ini merupakan jasa layanan yang diminati para pelanggan, jasa layanan ini dapat digunakan berbagai kalangan kapan pun dan dimana pun. Berbagai tarif dan banyaknya pelanggan relatif tergantung bagaimana pelayanan yang diberikan dari setiap masing-masing tempat jasa laundry. Dengan berkembangnya jasa laundry di berbagai tempat, dan hasil laundry yang memuaskan membuat banyak masyarakat lebih nyaman dan mempercayakan pada pelayanan jasa tersebut. Dengan banyaknya transaksi yang terjadi ditiap harinya, maka dengan adanya sistem informasi jasa laundry ini dalam proses transaksi dapat memberikan kemudahan dan keakuratan dalam setiap transaksi yang terjadi dan juga penyusunan laporan yang ada. Petugas dapat lebih terbantu dengan adanya sistem informasi. Dengan adanya sistem informasi yang ada sekarang mungkin dapat lebih dikembangkan lagi pada penelitian berikutnya, diharapkan dapat juga membuat sistem informasi yang dapat membantu pelanggan untuk dapat daftar secara online dan dapat diberikan pelayanan delivery atau antar jemput untuk barang yang ingin dicuci dan sudah selesai di proses.

\section{Ucapan Terima Kasih}

Alhamdulilah Puji Syukur kepada Alloh SWT, karena atas kehendak dan ridhaNya peneliti dapat menyelesaikan karya ilmiah ini. Kami sadari penelitian ini tidak akan selesai tanpa doa, dukungan dan dorongan dari berbagai pihak. Adapun dalam kesempatan ini peneliti ingin mengucapkan banyak terima kasih kepada penyelenggara jurnal Informatics For Educators And Professionals yang telah memberi kesempatan kepada kami dan membantu kami para penulis untuk penerbitan karya ilmiah ini. 


\section{Referensi}

[1] L. S. Helling, "Perancangan Sistem Informasi Pelayanan Pelanggan Pada Citra Laundry Bogor," INTENSIF J. IIm. Penelit. Dan Penerapan Teknol. Sist. Inf., vol. 2, p. 68, 2018.

[2] S. Rosyida and V. Riyanto, "Sistem Informasi Pengelolaan Data Laundry Pada Rumah," vol. 5, no. 1, pp. 29-36, 2019.

[3] R. S. Hidayat, A. Winarno, and M. Kom, "Perancangan Sistem Informasi Pelayanan Jasa Laundry Pada Hello Laundry," 2014.

[4] E. W. Lestari and N. Yani, "Perancangan Pembelajaran Daring SMK PGRI 1 Jakarta," vol. XXI, no. 1, pp. 9-16, 2019.

[5] E. W. Lestari, F. Ramdani, R. P. Lunak, U. Bina, and S. Informatika, "Sistem Informasi Pelayanan Jasa Cuci Kendaraan Bermotor Berbasis Web," vol. 8, no. 1, 2020.

[6] N. Y. Lestari, Endah Wiji; Mirchandini, "Sistem Informasi Pendaftaran Anggota Baru Pada palang Merah Indonesia (PMI) Jakarta,” Paradigma, vol. XXI, pp. 173-178, 2019.

[7] Yurinda, Software Engineering. Yogyakarta: Deepublish, 2017.

[8] H. Kamil and A. Duhani, "Pembangunan Sistem Informasi Pelayanan Jasa Laundry Berbasis Web Dengan Fitur Mobile Pada 21 Laundry Padang," no. November, pp. 1-9, 2016.

[9] B. Mulyadi and A. Tedyyana, "Aplikasi Sistem Pemesanan Jasa Laundry ( E- Laundry ) Berbasis Android," vol. x, no. x, pp. 48-56, 2019.

[10] D. Puspitasari and E. Noviyanti, "Sistem Informasi Jasa Laundry Berbasis Desktop pada Toko Syafira Laundry,” vol. 4, no. 2, pp. 133-142, 2020. 